\title{
Ion-Exchanged Binuclear Clusters As Active Sites of Selective Oxidation over Zeolites
}

\author{
G. M. Zhidomirov, ${ }^{\dagger, *}$ A. V. Larin, ${ }^{*, \dagger}$ D. N. Trubnikov, ${ }^{\dagger}$ and D. P. Vercauteren ${ }^{\S}$ \\ Department of Chemistry, Moscow State University, Moscow, GSP-2, 119992, Russia, \\ Boreskov Institute of Catalysis, SO RAN, Novosibirsk, 630090, Russia, and University of Namur (FUNDP), \\ Rue de Bruxelles 61, B-5000 Namur, Belgium
}

Received: September 23, 2008; Revised Manuscript Received: February 05, 2009

\begin{abstract}
A new catalytic oxidation cycle over binuclear $\mathrm{Zn}$ - and Ca-cation clusters in zeolites is proposed. Intermediate active clusters appear due to trapping of dioxygen. $\mathrm{CO}$ oxidation is considered as a model reaction over a cluster located in an 8-membered (8R) ring. Geometries of active clusters involved in the catalytic cycle vary depending on the nature and size of the cation. Reagents, transition states, and products have been optimized at the isolated cluster level considering DFT functionals (B3LYP, B3P86, and B3PW91) with the 6-31G* or $6-311++\mathrm{G}^{* *}$ basis sets. Moderate activation energies of 23.0 and $35.7 \mathrm{kcal} / \mathrm{mol}$ at the $\mathrm{B} 3 \mathrm{LYP} / 6-31 \mathrm{G}^{*}$ level are obtained for $\mathrm{CO}$ oxidation over $\mathrm{Zn}$ - and Ca-clusters, respectively.
\end{abstract}

\section{Introduction}

Oxidation by $\mathrm{O}_{2}$ in zeolite forms with alkaline and alkaline earth cations has long been a topic of discussion with respect to various organic molecules. ${ }^{1-5}$ For example, oxidation of small alkenes, ${ }^{1-3}$ toluene, ${ }^{4,6}$-xylene, ${ }^{6}$ cyclohexane,${ }^{5,7}$ and propane, ${ }^{8}$ and of $\mathrm{CO}$ within frameworks involving complex mechanisms with noble metal clusters ${ }^{9}$ has already been studied in details. As well, the case of $\mathrm{CO}$ oxidation in $\mathrm{CaY}$ seems also relevant even if $\mathrm{O}_{2}$ is not directly used under experimental conditions. ${ }^{10}$ Oxidation over alkaline and alkaline earth cationic forms was considered as a different class compared to other oxidation reactions with $\mathrm{O}_{2}$ participation. ${ }^{8}$ The mechanism is interpreted as a stabilization of an "organic molecule $-\mathrm{O}_{2}$ " ion pair with an essential charge transfer. ${ }^{1-5}$ The primary role of the electric field for such stabilization was hence emphasized for both alkaline and alkaline earth cations. The complex dependence of the reaction yield on the electric field cannot however ascertain a unique oxidation mechanism. Moreover, it is difficult to apply the idea of ion pair transition state with large charge transfer to the $\mathrm{CO}-\mathrm{O}_{2}$ case.

The appearance of the $[\mathrm{M}-\mathrm{O}-\mathrm{M}]^{2+}$ species with extra-lattice oxygen (ELO) is very probable upon increasing the $\mathrm{Si} / \mathrm{Al}$ ratio of the zeolite framework as shown by both numerous experimental and theoretical studies. Experimental evidence was first found by Boudart and co-workers, who observed redox pairs of iron ions in FeY. ${ }^{11}$ The bridging position of oxygen was confirmed by Mössbauer ${ }^{12}$ and IR ${ }^{13}$ spectroscopy. The catalytic activity of such a system is associated with both the binuclear structure and peculiar chemical properties of ELO, which vary with the framework type. Much attention was paid to the redox properties of the binuclear structures ${ }^{14}$ that were assumed to be responsible for the kinetics of catalytic reactions, for example, the concentration oscillations of $\mathrm{N}_{2} \mathrm{O}$ decompositions. ${ }^{15,16}$ The majority of theoretical studies relative to oxo-binuclear structures in zeolites were devoted to the structural and chemical properties of oxygen-bridged $[\mathrm{Cu}-\mathrm{O}-\mathrm{Cu}]^{2+}$ ion pairs, with regard to the problem of catalytic processes for selective NOx reductions. ${ }^{17-20}$

\footnotetext{
* Corresponding author. E-mail: nasgo@yandex.ru.

${ }^{\dagger}$ Moscow State University.

* Boreskov Institute of Catalysis.

$\S$ University of Namur.
}

Oxo-bridged binuclear $[\mathrm{Zn}-\mathrm{O}-\mathrm{Zn}]^{2+}$ structures were discussed considering the problem of dehydrogenations of light alkanes. ${ }^{21}$ Finally, let us mention methanol to olefins (MTO) decomposition over $[\mathrm{Fe}-\mathrm{O}-\mathrm{Fe}]^{2+}$ studied in refs 22 and 23.

In this paper, another possibile oxidation mechanism is suggested and discussed with respect to $\mathrm{CO}$ oxidation for $\mathrm{Zn}$ and Ca-cation exchanged zeolites. Assuming the appearance of two closely located $\mathrm{Si} / \mathrm{Al}$ replacements and two respective $\mathrm{Me}$ cations, we have found a series of new $\mathrm{Me}_{2} \mathrm{O}_{\mathrm{X}}(X=1-3)$ oxide clusters which could serve as oxidation centers in zeolites.

First we describe the computational strategy which is modified versus the usual cluster approach while increasing the cluster size by adding and optimizing an extra layer of nearest $\mathrm{O}$ atoms. In the first part of the Results, we will discuss the optimized geometries and heats of formation. The main attention is paid to the comparison of the oxidation of $\mathrm{CO}$ over the $\mathrm{Zn}$ - and $\mathrm{Ca}$ clusters in the $\mathrm{Me}_{2} \mathrm{O}_{2}$ form considering small and large clusters and various DFT functionals. In the last part of the Results, $\mathrm{CO}$ oxidation is studied over $\mathrm{Ca}_{2} \mathrm{O}_{3}$ at both the B3LYP and MP2 levels to evaluate the accuracy of the B3LYP computations.

\section{Computational Details}

First, we fully optimized the geometry of a supercell with two primitive cells of $\mathrm{Zn}$-form of mordenite (MOR) using the GULP code ${ }^{24}$ and Catlow force field (FF) ${ }^{25,26}$ with $\mathrm{Al}$ in position $\mathrm{T} 4{ }^{27}$ on the opposite sides of the large channel in ZnMOR. One of the $8 \mathrm{R}$ rings which opens the side pockets in ZnMOR was isolated from the $3 \mathrm{D}$ structure and the second $\mathrm{Si}$ atom was replaced by $\mathrm{Al}$ at $\mathrm{T} 4$. Keeping the $\mathrm{Zn}$ cation near the $8 \mathrm{R}$ ring and filling the ruptured $\mathrm{T}-\mathrm{O}$ bonds of all $\mathrm{T}$ atoms $(\mathrm{T}=\mathrm{Si}$ and $\mathrm{Al}$ ) by capping hydrogen atoms, one reached a neutral fragment $\mathrm{ZnAl}_{2} \mathrm{Si}_{6} \mathrm{O}_{8} \mathrm{H}_{16}$. The initial $\mathrm{T}-\mathrm{H}$ bond lengths were fixed at 1.4 $\AA$, close to the optimal value as estimated at the B3LYP/6$31 \mathrm{G}^{*}$ level. The $\mathrm{T}-\mathrm{H}$ lengths were further optimized using Gaussian $03^{28}$ at fixed $\mathrm{O}-\mathrm{T}-\mathrm{H}$ and $\mathrm{T}^{\prime}-\mathrm{O}-\mathrm{T}-\mathrm{H}$ angles and fixed positions of the other atoms. Then, $\mathrm{H}$ atoms only were fixed and the coordinates of the other atoms were varied also at the B3LYP/6-31G* level, as most results obtained here.

An important step was then to check the influence of spatial restraints on the resulting energy and geometry for a larger fragment, obtained by addition of a layer of 16 oxygen atoms 


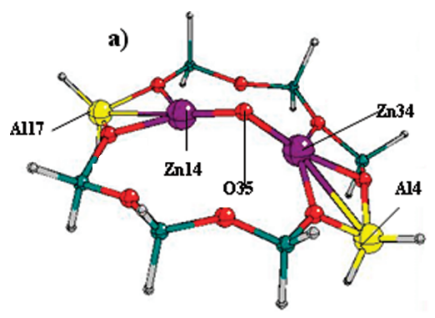

b)
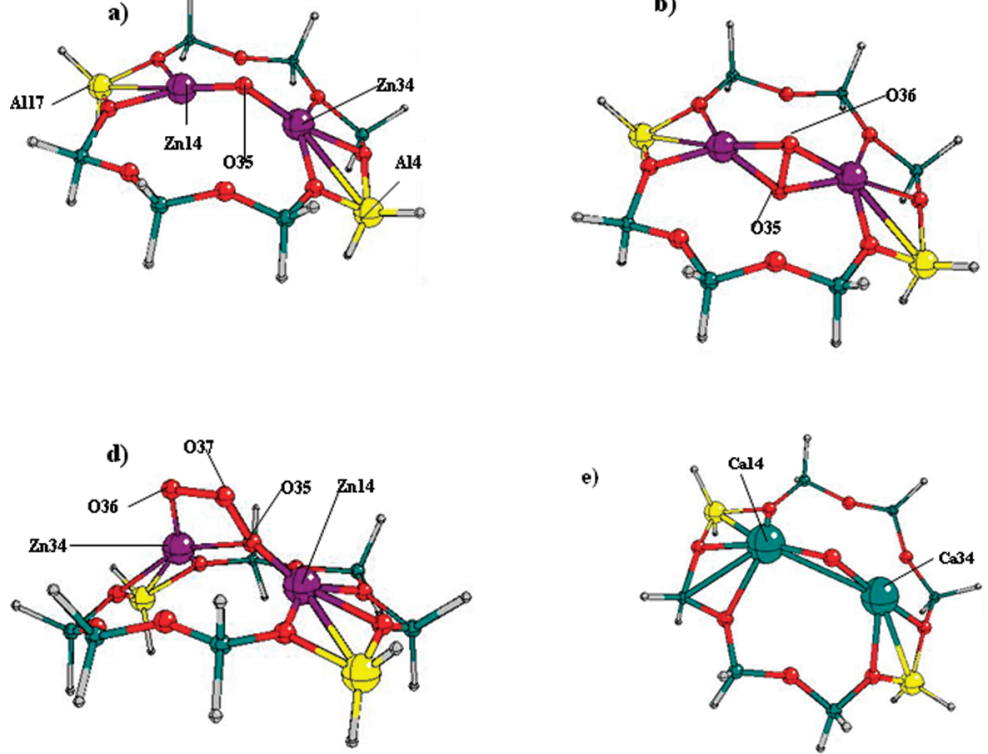

g)

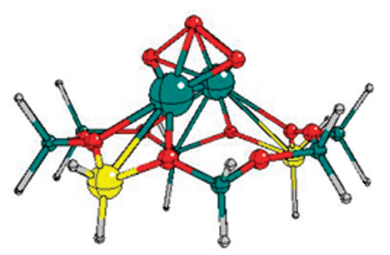

e)

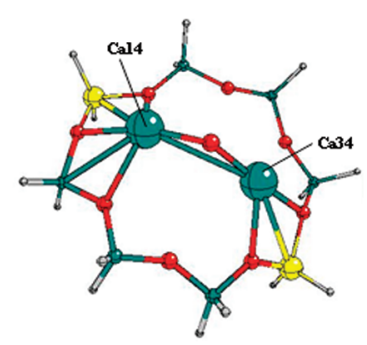

h)

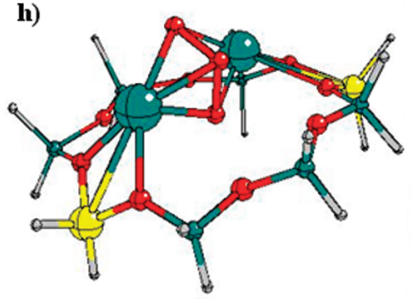

c)

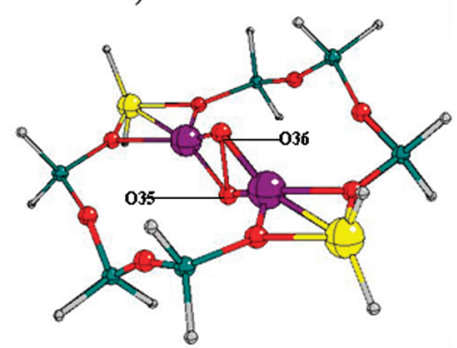

f)
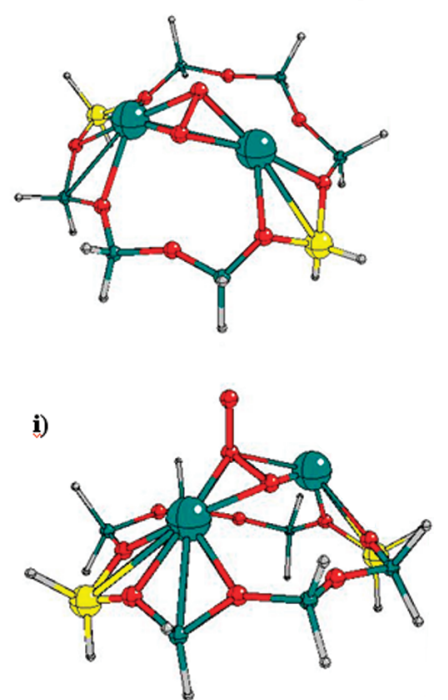

Figure 1. Structures of the small $\mathrm{Me}_{2} \mathrm{O}_{X}(8 \mathrm{R})$ clusters, $\mathrm{Me}=\mathrm{Zn}(\mathrm{a}-\mathrm{d}), \mathrm{Me}=\mathrm{Ca}(\mathrm{e}-\mathrm{i})$ for $X=1$ (a, e), $X=2$ (b, c, f), $X=3$ (d, g, h, i) for restrained optimizations, i.e., with fixed $\mathrm{H}$ atoms as described in the text (a-b, d-i) or full optimizations (c). Rotated (h) and inverted (i) conformers of $\mathrm{Ca}_{2} \mathrm{O}_{3}(8 \mathrm{R})$ are also shown. Atomic labels of Figure 1 are used in Tables 1-3. The color code is: $\mathrm{Zn}$ in purple, Ca in green (larger spheres), O in red, $\mathrm{Si}$ in green (smaller spheres), $\mathrm{Al}$ in yellow, $\mathrm{H}$ in gray.

to the $8 \mathrm{R}$ ring $\mathrm{T}$ atoms instead of $\mathrm{H}$. To add the $\mathrm{O}$ atoms, the optimized small cluster was embedded in the initial crystallographic position. It was achieved via a series of rotations of the small cluster as a whole, i.e., with fixed relative optimized coordinates in order to reach minimal distances between the $\mathrm{O}$ atoms in crystallographic positions and the optimized $\mathrm{H}$ atoms. The already optimized $\mathrm{H}$ atoms were replaced by the nearest $\mathrm{O}$ atoms in crystallographic positions while additional $\mathrm{H}$ atoms were added to the new $\mathrm{O}$ atoms in the direction of the nearest $\mathrm{T}$ atoms. Then the optimization procedure of the $\mathrm{H}$ coordinates was repeated as for the smaller cluster.

To determine the reaction coordinate for $\mathrm{CO}$ oxidation, we applied the QST3 algorithm as supplied with Gaussian $03^{28}$ considering the optimized geometries of the reagents and products.

\section{Results}

Relative Stabilities and Geometries of the $\mathrm{Me}_{2} \mathrm{O}_{X}(8 \mathrm{R})$ Clusters. The bridge $[\mathrm{Me}-\mathrm{O}-\mathrm{Me}]^{2+}$ geometry has already been discussed in the literature for $\mathrm{Me}=\mathrm{Zn},{ }^{21,29} \mathrm{Cu},{ }^{15,17-20}$ and Fe. ${ }^{16,22,23}$ Herein, different stationary geometries of $\mathrm{Me}_{2} \mathrm{O}_{X}$ oxide clusters $(X=1-3)$ in cationic positions of the $8 \mathrm{R}$ ring were first optimized for $\mathrm{Me}=\mathrm{Zn}$ and $\mathrm{Ca}$. The $\mathrm{Zn}_{2} \mathrm{O}$ (Figure 1a) and $\mathrm{Ca}_{2} \mathrm{O}$ (Figure 1e) models are quite similar while large differences are observed between $\mathrm{Zn}_{2} \mathrm{O}_{2}$ (Figure $1 \mathrm{~b}$ ) and $\mathrm{Ca}_{2} \mathrm{O}_{2}$ (Figure 1f) or between $\mathrm{Zn}_{2} \mathrm{O}_{3}$ (Figure 1d) and $\mathrm{Ca}_{2} \mathrm{O}_{3}$ (Figure 1g). These different geometries are mainly conserved at different stages of the $\mathrm{CO}$ oxidation presented below in detail (Figure 2). The $\mathrm{Zn}-\mathrm{O}$ distances are shorter in the $\mathrm{Zn}_{2} \mathrm{O}(8 \mathrm{R})$ models (Table 1) compared to those in $\mathrm{Zn}_{2} \mathrm{O}_{2}$ (8R) (Table 2). For $\mathrm{Ca}_{2} \mathrm{O}(8 \mathrm{R})$, two pseudopotential basis sets for $\mathrm{Ca}$ were also tested denoting the appropriate quality of the LANL2DZ basis (Table 3), which however leads to higher atomic charges than the values obtained with 6-31G*.

If the existence of $[\mathrm{Zn}-\mathrm{O}-\mathrm{Zn}]^{2+}$ is accepted conventionally in literature, ${ }^{21,29}$ it is not the case of $[\mathrm{Ca}-\mathrm{O}-\mathrm{Ca}]^{2+}$. We therefore evaluated the respective exothermic effects of the $\mathrm{Me}_{2} \mathrm{O}(8 \mathrm{R})$ formation according to the reaction

$$
\mathrm{Me}(8 \mathrm{R})+\mathrm{Me}(\mathrm{OH})_{2} \rightarrow \mathrm{Me}_{2} \mathrm{O}(8 \mathrm{R})+\mathrm{H}_{2} \mathrm{O}
$$

It gave -52.3 and $-85.3 \mathrm{kcal} / \mathrm{mol}$ at the $\mathrm{B} 3 \mathrm{LYP} / 6-31 \mathrm{G}^{*}$ level for $\mathrm{Me}=\mathrm{Ca}$ and $\mathrm{Zn}$, respectively, that can be considered as the thermodynamic confirmation of the $\mathrm{Me}_{2} \mathrm{O}(8 \mathrm{R})$ formation.

For the $\mathrm{Zn}$ cations, the optimized structures of $\mathrm{Zn}_{2} \mathrm{O}_{2}$ (Figure 1b) and $\mathrm{Zn}_{2} \mathrm{O}_{3}$ (Figure 1d) clusters are oriented in a plane that is nearly perpendicular to the $8 \mathrm{R}$ ring and that passes through both $\mathrm{Zn}$ cations. The possible parallel orientation of the $\mathrm{O}-\mathrm{O}$ part versus the $8 \mathrm{R}$ ring was checked but it is not stable for the $\mathrm{Zn}$ complex. The rhomb $\mathrm{Zn}_{2} \mathrm{O}_{2}$ geometry is similar to the square type clusters that were optimized for $\mathrm{Al}_{2} \mathrm{O}_{2}{ }^{30}$ and $\mathrm{Ga}_{2} \mathrm{O}_{2} \cdot{ }^{31,32}$ Due to spatial limits imposed by the larger ionic radii of $\mathrm{Ca}^{2+}$ $(1.00 \AA)^{33}$ versus $\mathrm{Zn}^{2+}(0.74 \AA)$, the rhomb $\mathrm{Ca}_{2} \mathrm{O}_{2}$ cluster is parallel to the $8 \mathrm{R}$ ring (Figure 1f) so that both $\mathrm{O}$ atoms of the peroxide $\mathrm{O}-\mathrm{O}$ moiety are more accessible for adsorbate molecules as compared to the one of $\mathrm{Zn}_{2} \mathrm{O}_{2}$ (Figure 1b). The presence of the peroxide $\mathrm{O}-\mathrm{O}$ part which can serve as an oxidizing reagent is the principal feature of the $\mathrm{Zn}_{2} \mathrm{O}_{2}$ and $\mathrm{Ca}_{2} \mathrm{O}_{2}$ clusters obtained herein versus $\mathrm{Al}_{2} \mathrm{O}_{2},{ }^{30} \mathrm{Ga}_{2} \mathrm{O}_{2},{ }^{31,32}$ and $\mathrm{Zr}_{2} \mathrm{O}_{3} .{ }^{34}$ 

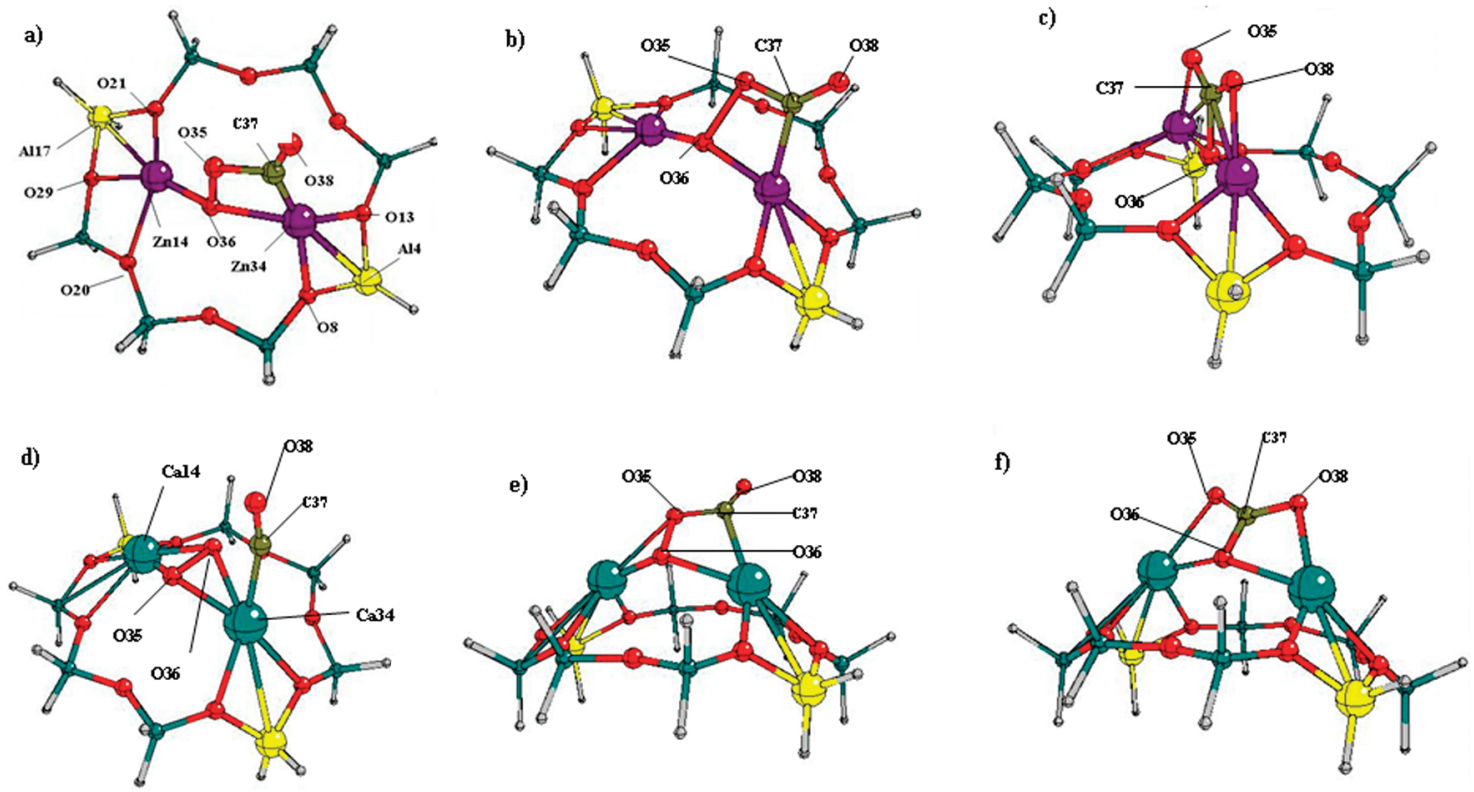

Figure 2. Structures of the reagent (a, d), transition state (b, e), and product clusters (c, f) for $\mathrm{CO}$ oxidation over the small optimized $\mathrm{Me}_{2} \mathrm{O}_{2}(8 \mathrm{R})$ clusters, $\mathrm{Me}=\mathrm{Zn}(\mathrm{a}-\mathrm{c}), \mathrm{Me}=\mathrm{Ca}(\mathrm{d}-\mathrm{f})$. Atomic labels of Figure 2 are used in Tables 2 and 3. The color code corresponds to the one of Figure $1 ; \mathrm{C}$ is in brown.

TABLE 1: Several Geometrical Parameters of the $\mathrm{Me}_{2} \mathrm{O}(8 \mathrm{R})$ Models (Distances in $\AA$, Angles in Degrees) Calculated at the B3LYP Level with $6-31 \mathrm{G} * a$

\begin{tabular}{|c|c|c|}
\hline parameter & $\mathrm{Ca}$ & $\mathrm{Zn}$ \\
\hline Me34-O35 & 2.118 & 1.766 \\
\hline $\mathrm{Me} 34 \cdot \cdots \mathrm{Al} 4$ & 3.202 & 2.834 \\
\hline $\mathrm{Me} 14-\mathrm{O} 35$ & 2.115 & 1.783 \\
\hline Me14...Al17 & 3.247 & 2.945 \\
\hline $\mathrm{Me} 14 \cdot \cdots \mathrm{Me} 34$ & 3.746 & 3.247 \\
\hline Me14-O35-Me34 & 124.48 & 132.47 \\
\hline
\end{tabular}

${ }^{a}$ The labels of the atomic positions are shown in Figure 1.

The $\mathrm{O}-\mathrm{O}$ length varies from $1.570 \AA$ for the $\mathrm{Ca}$ cluster (not shown in Table 2) versus $1.646 \AA$ for the $\mathrm{Zn}$ one (Table 2), which is due to both the cationic size and the spatial restrictions being distorted relative to the experimental gas value $r_{\mathrm{e}}=1.201$ $\AA^{35}$ or the theoretical value of $1.214 \AA$ obtained at the B3LYP/ 6-31G* level. For comparison, the $\mathrm{O} \cdots \mathrm{O}$ distance varies from $2.560 \AA$ in $\mathrm{Al}_{2} \mathrm{O}_{2}{ }^{30}$ to $2.734 \AA$ in $\mathrm{Ga}_{2} \mathrm{O}_{2}{ }^{31}$ In order to evaluate the influence of the deformation of the MOR $8 \mathrm{R}$ ring on the $\mathrm{Zn}_{2} \mathrm{O}_{2}$ geometry, we performed a full geometry optimization without fixed $\mathrm{H}$ atoms which resulted in a highly symmetric $8 \mathrm{R}$ ring and rhomb $\mathrm{Zn}_{2} \mathrm{O}_{2}$ (Figure 1c). Table 2 shows that the geometrical parameters of the fully optimized rhomb $\mathrm{Zn}_{2} \mathrm{O}_{2}$ do not deviate essentially versus the optimization with spatially imposed restraints (Figure 1b), with the exception of the deviation from the plain rhomb $\mathrm{Zn}_{2} \mathrm{O}_{2}$ (Figure 1c) with a $\mathrm{Zn} 14-\mathrm{O} 36-\mathrm{O} 35-\mathrm{Zn} 34$ torsion angle of $161.86^{\circ}$. It signifies that the reactivity of the $\mathrm{Zn}_{2} \mathrm{O}_{2}$ cluster is not the result of a particular deformation in the 8R ring of MOR. We should add here that we did not succeed in optimizing the geometry of an isolated $\mathrm{Zn}_{2} \mathrm{O}_{2}$ cluster, i.e., without $8 \mathrm{R}$ fragment, neither at the B3LYP level, nor HF.

The ozone like $\mathrm{O}_{3}$ part of the $\mathrm{Me}_{2} \mathrm{O}_{3}$ clusters has a similar angular $(\mathrm{O}-\mathrm{O}-\mathrm{O})$ moiety of A-letter shape for both $\mathrm{Me}=\mathrm{Zn}$ (Figure 1d) and $\mathrm{Ca}$ (Figure 1g), but the orientations of the $\mathrm{O}_{3}$ are different relative to the cations (Table 4). The $\mathrm{O}-\mathrm{O}$ distances and $\mathrm{O}-\mathrm{O}-\mathrm{O}$ angle of the $\mathrm{O}_{3}$ part vary slightly between $\mathrm{Zn}_{2} \mathrm{O}_{3}$ $\left(1.422 \AA, 1.494 \AA, 102.84^{\circ}\right)$ and $\mathrm{Ca}_{2} \mathrm{O}_{3}(1.493 \AA, 1.495 \AA$, $105.56^{\circ}$ ) at the B3LYP/6-31G* level. For $\mathrm{Zn}_{2} \mathrm{O}_{3}$, the two "legs"
TABLE 2: Several Geometrical Parameters of the $\mathrm{Zn}_{2} \mathrm{O}_{2}$ (8R) Models (Distances in $\AA$, Angles in Degrees) Calculated at the B3LYP/6-31G* Level with Full $(-6542.707473 \mathrm{au})$ and Restrained $(-6542.646315 \mathrm{au})$ Optimizations $^{a}$

\begin{tabular}{|c|c|c|}
\hline parameter & full & restrained \\
\hline Zn34-O35 & 1.920 & 1.912 \\
\hline Zn34-O36 & 1.920 & 1.895 \\
\hline $\mathrm{Zn} 34 \cdots \mathrm{Al} 4$ & 2.830 & 2.725 \\
\hline Zn14-O35 & 1.920 & 1.935 \\
\hline Zn14-O36 & 1.920 & 1.921 \\
\hline 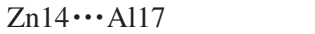 & 2.830 & 2.859 \\
\hline $\mathrm{O} 35-\mathrm{O} 36$ & 1.648 & 1.646 \\
\hline $\mathrm{Zn} 14 \cdots \mathrm{Zn} 34$ & 3.468 & 3.417 \\
\hline $\mathrm{Zn} 14-\mathrm{O} 35-\mathrm{Zn} 34$ & 129.17 & 125.28 \\
\hline $\mathrm{Zn} 14-\mathrm{O} 36-\mathrm{Zn} 34$ & 129.17 & 127.07 \\
\hline $\mathrm{O} 35-\mathrm{Zn} 34-\mathrm{O} 36$ & 50.83 & 51.24 \\
\hline $\mathrm{O} 35-\mathrm{Zn} 14-\mathrm{O} 36$ & 50.83 & 50.55 \\
\hline $\mathrm{Zn} 14-\mathrm{O} 36-\mathrm{O} 35-\mathrm{Zn} 34$ & 179.96 & 161.86 \\
\hline
\end{tabular}

${ }^{a}$ The labels of the atomic positions are shown in Figure 2.

of the A-shape are linked to one of the two $\mathrm{Zn}$ cations whereas one of the two $\mathrm{O}$ atoms (O35) is also linked to the second $\mathrm{Zn}$ atom (Figure 1d). The same A-shape $\mathrm{O}_{3}$ part for $\mathrm{Ca}_{2} \mathrm{O}_{3}$ is turned perpendicularly to the $\mathrm{Ca} \cdots \mathrm{Ca}$ axis and symmetrically coordinated to both $\mathrm{Ca}$ cations (Figure 1g). Two additional "inverted" and "rotated" isomers with local minimum for $\mathrm{Ca}_{2} \mathrm{O}_{3}$ were observed (Figure 1h,i) being less stable than the symmetric form (Figure $1 \mathrm{~g}$ ). The $\mathrm{O}_{3}$ moiety keeps its $\mathrm{O}-\mathrm{O}$ bonds and $\mathrm{O}-\mathrm{O}-\mathrm{O}$ angle in the "inverted" form (less stable by $26.6 \mathrm{kcal} /$ mol at the B3LYP/6-31G* level, both Ca atoms are symmetrically oriented toward two $\mathrm{O}$ atoms of one $\mathrm{O}-\mathrm{O}$ side of the $\mathrm{O}_{3}$ part, Figure 1i) and the "rotated" form (less stable by $9.7 \mathrm{kcal} / \mathrm{mol}$, Figure $1 \mathrm{~h}$ ). The rotated $\mathrm{Ca}_{2} \mathrm{O}_{3}$ conformer with the $\mathrm{O}-\mathrm{O}$ distances of 1.497 and $1.504 \AA$ and $\mathrm{O}-\mathrm{O}-\mathrm{O}$ angle of $105.34^{\circ}$ corresponds to an approximate rotation by $90^{\circ}$ of the symmetric form (Figure $1 \mathrm{~g}$ ) around the $\mathrm{Ca} \cdots \mathrm{Ca}$ axis. Different initial models were tested and led to the same conformers. The invariance of the $\mathrm{O}-\mathrm{O}$ distances and $\mathrm{O}-\mathrm{O}-\mathrm{O}$ angle of the $\mathrm{O}_{3}$ geometry confirms the stability of the $\mathrm{Ca}_{2} \mathrm{O}_{3}$ cluster. Additionally, we verified that the Zn type geometry as 
TABLE 3: Mulliken Charges $q$ (e) and Several Geometrical Parameters for the Me14-O35-Me34 Moiety of the Me $20(8 \mathrm{R})$ Models (Distances in $\AA$, Angles in Degrees) Calculated at the B3LYP Level with Three Basis Sets for Me = Ca and with 6-31G* for $\mathrm{Me}=\mathrm{Zn}^{a}$

\begin{tabular}{|c|c|c|c|c|}
\hline \multirow[b]{2}{*}{ parameter } & \multicolumn{4}{|c|}{ basis set (Me) } \\
\hline & Ca/LANL1DZ & $\mathrm{Ca} / \mathrm{LANL} 2 \mathrm{DZ}$ & $\mathrm{Ca} / 6-31 \mathrm{G}^{*}$ & $\mathrm{Zn} / 6-31 \mathrm{G}^{*}$ \\
\hline$q(\mathrm{Me} 14)$ & 1.342 & 1.170 & $0.913^{b}$ & $0.776^{d}$ \\
\hline Me14...Al17 & 3.131 & 3.247 & 3.247 & 2.945 \\
\hline $\mathrm{Me} 14-\mathrm{O} 35$ & 2.024 & 2.134 & 2.115 & 1.783 \\
\hline $\mathrm{Me} 34-\mathrm{O} 35$ & 2.021 & 2.136 & 2.118 & 1.766 \\
\hline $\mathrm{Me} 14-\mathrm{O} 35-\mathrm{Me} 34$ & 132.19 & 127.32 & 124.48 & 132.47 \\
\hline
\end{tabular}

${ }^{a}$ The 6-31G* basis is applied to the framework atoms. The labels of the atomic positions are shown in Figure $1 .{ }^{b}$ NBO charge 1.792 e. ${ }^{c} \mathrm{NBO}$ charge -1.648 e. ${ }^{d} \mathrm{NBO}$ charge 1.608 e. ${ }^{e} \mathrm{NBO}$ charge $-1.468 \mathrm{e}$.

TABLE 4: Several Geometrical Parameters of the $\mathrm{Me}_{2} \mathrm{O}_{3}(8 \mathrm{R})$ Models (Distances in $\AA$, Angles in Degrees) Calculated at the B3LYP/6-31G* Level for Framework Atoms and 6-31G*(Me) or LANL2DZ(Me) Basis Set for the Me Cations, Me $=\mathrm{Ca}$ or $\mathrm{Zn}^{a}$

\begin{tabular}{|c|c|c|c|c|}
\hline \multirow[b]{2}{*}{ parameter } & \multicolumn{2}{|c|}{$\mathrm{Ca}$} & \multicolumn{2}{|c|}{$\mathrm{Zn}$} \\
\hline & LANL2DZ & $6-31 \mathrm{G}^{*}$ & LANL2DZ & 6-31G* \\
\hline $\mathrm{Me} 34-\mathrm{O} 36$ & 2.324 & 2.312 & 1.940 & 1.882 \\
\hline Me34‥OO37 & 2.334 & 2.324 & 2.539 & 2.512 \\
\hline Me14 $\cdots$ O36 & 2.347 & 2.336 & 3.848 & 3.854 \\
\hline $\mathrm{Me} 14-\mathrm{O} 35$ & 2.509 & 2.484 & 1.907 & 1.848 \\
\hline $\mathrm{Me} 14 \cdot \cdots \mathrm{O} 37$ & 2.336 & 2.328 & 2.728 & 2.696 \\
\hline $\mathrm{O} 37-\mathrm{O} 35$ & 1.498 & 1.495 & 1.499 & 1.494 \\
\hline Me14 $\cdots$ Me34 & 3.686 & 3.661 & 3.709 & 3.709 \\
\hline $\mathrm{O} 36-\mathrm{O} 37-\mathrm{O} 35$ & 104.86 & 105.56 & 104.25 & 102.84 \\
\hline
\end{tabular}

${ }^{a}$ The labels of the atomic positions are shown in Figure 1d.

TABLE 5: Heats of Reactions (kcal/mol) of the Oxidation Reactions (eq 2, First Three Lines) and Heat of Reaction/Activation Barrier of CO Oxidation Reaction (eq 3a, Fourth Line) over the Me-Clusters (Me = Zn or Ca) Calculated at the B3LYP/ 6-31G* Level $^{a}$

\begin{tabular}{lccc}
\hline \multicolumn{1}{c}{ reaction } & $\mathrm{Zn} / 6-31 \mathrm{G}^{*}$ & $\mathrm{Ca} / 6-31 \mathrm{G}^{*}$ & $\mathrm{Ca} / \mathrm{LANL} 2 \mathrm{DZ}$ \\
\hline $\mathrm{Me}-\mathrm{O}-\mathrm{Me}+1 / 2 \mathrm{O}_{2} \rightarrow \mathrm{Me}-\mathrm{O}_{2}-\mathrm{Me}$ & -23.9 & $-24.8,-27.9^{b}$ & -35.7 \\
$\mathrm{Me}-\mathrm{O}_{2}-\mathrm{Me}+1 / 2 \mathrm{O}_{2} \rightarrow \mathrm{Me}-\mathrm{O}_{3}-\mathrm{Me}$ & 39.0 & $-6.1,-12.7^{b}$ & -4.9 \\
$\mathrm{Me}-\mathrm{O}-\mathrm{Me}+\mathrm{O}_{2} \rightarrow \mathrm{Me}-\mathrm{O}_{3}-\mathrm{Me}$ & 13.1 & $-30.9,-40.6^{b}$ & -40.6 \\
$\mathrm{Me}-\mathrm{O}_{2}-\mathrm{Me}+\mathrm{CO} \rightarrow \mathrm{Me}_{2} \mathrm{CO}_{3}{ }^{c}$ & $110.0 / 23.0,114.3 / 18.8^{d, e}, 111.9 / 22.2^{d}$, & $106.9 / 35.7,108.6 / 33.5^{d}$ & $108.1 / 31.5$
\end{tabular}

${ }^{a} 8 \mathrm{R}$ notation of the zeolite part with the $\mathrm{Al}-(\mathrm{O}-\mathrm{Si})_{3}-\mathrm{O}-\mathrm{Al}$ alternation is omitted below for shortness. ${ }^{b}$ At the $\mathrm{MP} 2 / 6-31 \mathrm{G}^{*}$ level. ${ }^{c} \mathrm{Heat}$ of reaction/activation barrier. ${ }^{d}$ With extended cluster (+16 oxygen atoms, Figure 4). ${ }^{e}$ LANL2DZ(Zn)/6-31G*(Si, Al, O, H, C) basis set. ${ }^{f}$ At the B3PW91 level. ${ }^{g}$ At the B3P86 level. ${ }^{h} 6-311++\mathrm{G}^{* *}$ basis set.

starting point for the $\mathrm{Ca}_{2} \mathrm{O}_{3}$ cluster led to the optimized symmetric form (Figure $1 \mathrm{~g}$ ). We here wish to add that all the details of geometry were equally well described for the $\mathrm{Zn}$ and $\mathrm{Ca}$ cations with the LANL2DZ basis versus the 6-31G* one (Table 4 for $\mathrm{Ca}_{2} \mathrm{O}_{3}$ ). The application of the LANL2DZ basis set will be much more important in future studies for heavier alkaline earth cations like $\mathrm{Sr}$ and $\mathrm{Ba}$ for which no 6-31G* basis set has been developed so far.

Finally, there is a qualitative difference between $\mathrm{Zn}$ and $\mathrm{Ca}$ versus the oxidation step from $\mathrm{Me}_{2} \mathrm{O}_{2}$ to $\mathrm{Me}_{2} \mathrm{O}_{3}$. It is observed for the calculated heats of reaction of the possible catalytic cycle based on the series of consequent $\mathrm{Me}_{2} \mathrm{O}_{X}$ oxide clusters (Table 5). All of the oxidation steps

$$
\mathrm{Me}_{2} \mathrm{O}_{X}(8 \mathrm{R})+\frac{1}{2} \mathrm{O}_{2} \rightarrow \mathrm{Me}_{2} \mathrm{O}_{X+1}(8 \mathrm{R})
$$

by molecular oxygen from $\mathrm{Me}_{2} \mathrm{O}$ to $\mathrm{Me}_{2} \mathrm{O}_{2}$, from $\mathrm{Me}_{2} \mathrm{O}$ to $\mathrm{Me}_{2} \mathrm{O}_{3}$, and from $\mathrm{Me}_{2} \mathrm{O}_{2}$ to $\mathrm{Me}_{2} \mathrm{O}_{3}$ are exothermic for Ca but not for Zn. For the latter, reaction (eq 2) is exothermic only for $X=1$.
CO Oxidation over $\mathrm{Me}_{2} \mathrm{O}_{2}(8 \mathrm{R})$ Clusters. The presence of the $\mathrm{O}_{2}$ moiety in $\mathrm{Ca}_{2} \mathrm{O}_{2}$ suggests the possible oxidation activity of the respective cation exchanged forms. Moreover, the consequent reaction steps (eq 2) for $X=1$ and 2 together with $\mathrm{CO}$ oxidation to $\mathrm{CO}_{2}$

$$
\mathrm{Me}_{2} \mathrm{O}_{2}(8 \mathrm{R})+\mathrm{CO} \rightarrow \mathrm{Me}_{2} \mathrm{O}(8 \mathrm{R})+\mathrm{CO}_{2}
$$

could be the part of the closed catalytic cycle with participation of molecular $\mathrm{O}_{2}$. To check the catalytic activity, we considered $\mathrm{CO}$ oxidation to $\mathrm{CO}_{2}$ (eq 3 ) which remains an important process from the industrial application and scientific points of view. The structures of the reagents (Figure 2a, d) are different for $\mathrm{Zn}$ (Figure $2 \mathrm{a}-\mathrm{c}$ ) and $\mathrm{Ca}($ Figure $2 \mathrm{~d}-\mathrm{f}$ ), whereas the structures of the transition states (TS) (Figure $2 \mathrm{~b}$, e) or products of $\mathrm{CO}$ oxidation (Figure $2 \mathrm{c}, \mathrm{f}$ ) are rather similar.

The $\mathrm{CO} / \mathrm{Zn}_{2} \mathrm{O}_{2}(8 \mathrm{R})$ reaction complex (Figure $2 \mathrm{a}$ ) differs from the geometry of the isolated $\mathrm{Zn}_{2} \mathrm{O}_{2}(8 \mathrm{R})$ cluster (Figure $1 \mathrm{~b}$ ) which is closer to the one of the TS complex (Figure 2b). The principal difference between the reaction and TS complexes is the shortening in the TS of the new $\mathrm{C}-\mathrm{O}$ bond in the forming $\mathrm{CO}_{2}$ 
(b)

(c)

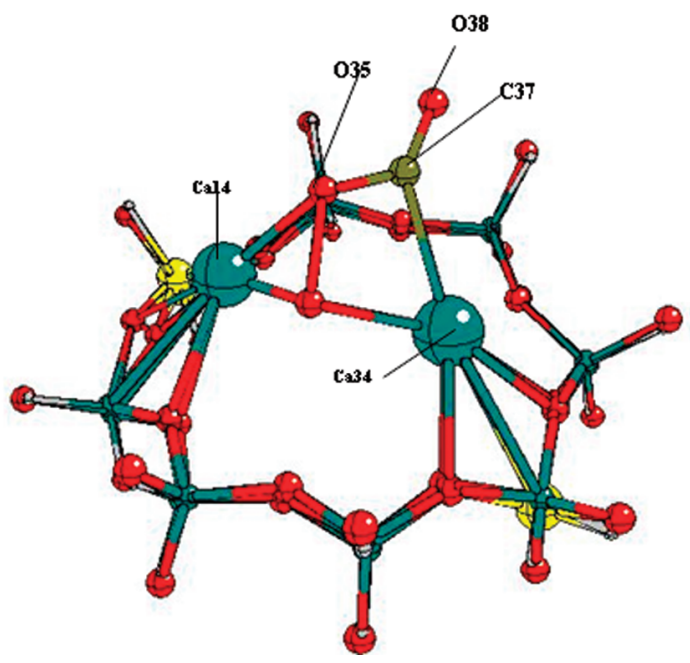

Figure 3. Structure of the optimized small cluster for the transition state of $\mathrm{CO}$ oxidation over $\mathrm{Ca}_{2} \mathrm{O}_{2}(8 \mathrm{R})$ (a), initial $8 \mathrm{R}$ ring of $\mathrm{ZnMOR}$ (b), and superimposed structures (c). The color code corresponds to the one of Figure 2.

molecule, i.e., $1.428 \AA$ in the reaction complex and $1.284 \AA$ in the TS, while the initial $\mathrm{C}-\mathrm{O}$ one varies very little, i.e., 1.197 $\AA$ in the reaction complex versus $1.219 \AA$ in the TS. The strong $\mathrm{CO}$ chemisorption over $\mathrm{Me}_{2} \mathrm{O}_{2}(8 \mathrm{R})$ results in a very high heat of adsorption of 18.7 and $13.3 \mathrm{kcal} / \mathrm{mol}$ for $\mathrm{Me}=\mathrm{Zn}$ and $\mathrm{Ca}$, respectively. We should add that the latter is nevertheless overestimated by at least $50 \%$ relative to the experimental heats of $\mathrm{CO}$ adsorption over the $\mathrm{CaNaA}$ zeolites, i.e., $9.1 \mathrm{kcal} / \mathrm{mol},{ }^{36}$ $6.1 \mathrm{kcal} / \mathrm{mol}$ over the $\mathrm{NaA},{ }^{36}$ and $6.4-6.2 \mathrm{kcal} / \mathrm{mol}$ over the $\mathrm{HMFI}^{37}$ zeolites.

On the opposite to the $\mathrm{Zn}$ cluster, $\mathrm{Ca}_{2} \mathrm{O}_{2}(8 \mathrm{R})$ holds its geometry in the reaction complex (Figure $2 \mathrm{~d}$ ). The $\mathrm{Ca}-\mathrm{C}$ and $\mathrm{Ca}-\mathrm{O}$ distances in the TS complex are much larger, i.e., 2.629, 2.852, and 2.405 $\AA$ for Ca34-C37, Ca34-O36, Ca14-O35 (using notations of Figure 2a) versus 2.093, 2.015, and 1.792 $\AA$ for the $\mathrm{Zn}-\mathrm{C}$ and $\mathrm{Zn}-\mathrm{O}$ distances in the $\mathrm{TS}$ of $\mathrm{CO} /$ (a)

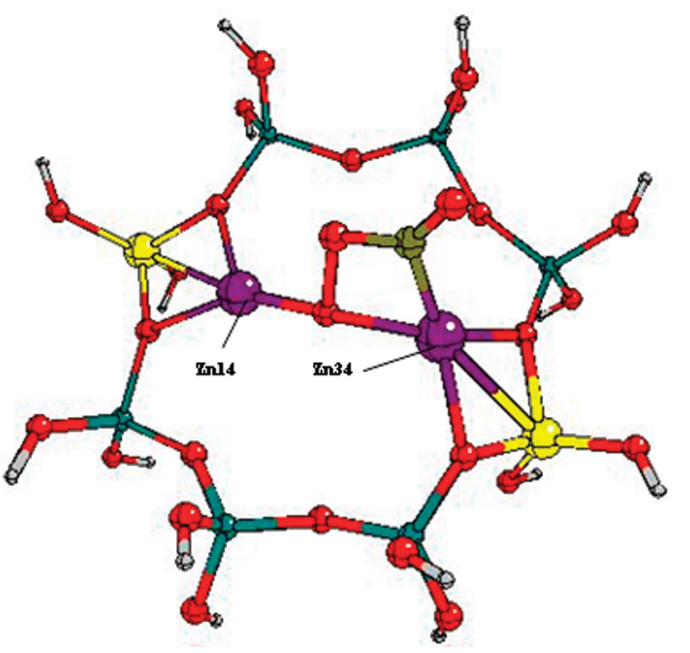

(b)

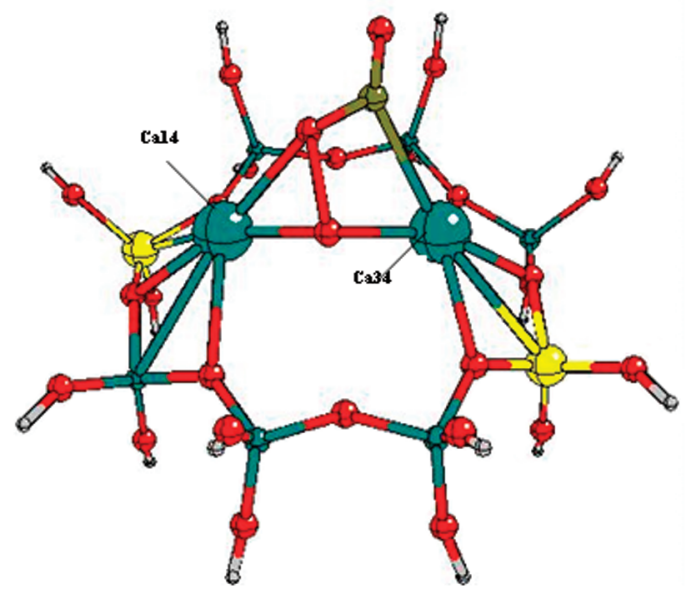

Figure 4. Structures of the extended optimized cluster for the transition state complexes for $\mathrm{CO}$ oxidation over $\mathrm{Me}_{2} \mathrm{O}_{2}(8 \mathrm{R})$ for $\mathrm{Me}=\mathrm{Zn}$ (a) and $\mathrm{Me}=\mathrm{Ca}(\mathrm{b})$. The color code corresponds to the one of Figure 2.

$\mathrm{Zn}_{2} \mathrm{O}_{2}(8 \mathrm{R})$ than the difference of $0.26 \AA$ between the ionic radius of $\mathrm{Zn}$ and $\mathrm{Ca} .{ }^{32}$ The minimal difference of $0.38 \AA$ is between the $\mathrm{Ca} 14-\mathrm{O} 36$ and $\mathrm{Zn} 14-\mathrm{O} 36$ bonds, i.e., 2.216 versus 1.836 $\AA$ (Figure 2c).

The most stable products correspond to the $\mathrm{CO}_{3}{ }^{2-}$ anion which is symmetrically coordinated to both Me cations for the $\mathrm{Zn}$ (Figure 2c) and $\mathrm{Ca}$ (Figure 2f) clusters

$$
\mathrm{Me}_{2} \mathrm{O}_{2}(8 \mathrm{R})+\mathrm{CO} \rightarrow \mathrm{Me}_{2} \mathrm{CO}_{3}(8 \mathrm{R})
$$

A closed catalytic cycle with participation of molecular $\mathrm{O}_{2}$ can thus be realized provided that $\mathrm{CO}_{2}$ could be desorbed from the $\mathrm{Zn}_{2} \mathrm{CO}_{3}(8 \mathrm{R})$ (Figure 2c) or $\mathrm{Ca}_{2} \mathrm{CO}_{3}(8 \mathrm{R}$ ) (Figure 2f) complex or from the less stable physisorbed $\mathrm{CO}_{2}$ state for $\mathrm{Zn}$ form, for example by heating. The $\mathrm{Zn}_{2} \mathrm{CO}_{3}(8 \mathrm{R})$ product (Figure 2c) is more stable by $32.6 \mathrm{kcal} / \mathrm{mol}$ as compared to the physisorbed $\mathrm{CO}_{2}$ molecule coordinated to only one $\mathrm{Zn}$ atom of $\mathrm{Zn}_{2} \mathrm{O}(8 \mathrm{R})$. Here, we should however add that the precise energy difference should be discussed while regarding accurately to the long-range effects for $\mathrm{CO}_{2}$ adsorption. For the $\mathrm{Ca}$ case, $\mathrm{CO}_{2}$ coordinates without energy barrier to both $\mathrm{Ca}$ cations of $\mathrm{Ca}_{2} \mathrm{O}_{2}(8 \mathrm{R})$, leading to $\mathrm{Ca}_{2} \mathrm{CO}_{3}(8 \mathrm{R})$ (Figure 2f). The indirect evidence of $\mathrm{CO}_{3}{ }^{2-}$ formation is coming from spectroscopic data for $\mathrm{CO} / \mathrm{CaY}$ at room as well as elevated temperatures. ${ }^{10}$ The time to remove $\mathrm{CO}_{2}$ from $\mathrm{CaY}^{10}$ is longer as compared to the short time of $\mathrm{CO}$ removal, i.e., 3-4 min, which can be assigned to the appearance of the $\mathrm{Me}_{2} \mathrm{CO}_{3}(n \mathrm{R})$ complex $(n=4,6$, or 12$)$ in $\mathrm{CaY}$. The 
TABLE 6: Relative Stabilities $\Delta Q$ of the $\mathrm{Ca}_{2} \mathrm{O}_{2}(8 \mathrm{R})$ Clusters, Respective Activation Barriers $\Delta E^{\#}$ of $\mathrm{CO}$ Oxidation, Heats of Reactions $\Delta U$, and Imaginary Frequencies $\omega$ along the Reaction Coordinates Calculated at the B3LYP/6-31G* Level for Different $\mathrm{Al}-(\mathrm{O}-\mathrm{Si})_{n}-\mathrm{O}-\mathrm{Al}$ Alternations Relative to the One for $n=3^{a}$

\begin{tabular}{rrrrr}
\hline$n$ & $\Delta Q$ & $\Delta E^{\#}$ & $\Delta U$ & $i \omega$ \\
\hline 1 & 26.5 & 35.3 & 121.6 & -673.7 \\
2 & 15.8 & 37.7 & 121.7 & -695.0 \\
3 & 0.0 & 35.7 & 106.9 & -750.3
\end{tabular}

${ }^{a}$ All energy values are in $\mathrm{kcal} / \mathrm{mol}$, and frequencies are in $\mathrm{cm}^{-1}$.

TABLE 7: $\Delta E^{\#}$ Activation Barriers of the $\mathrm{Ca}_{2} \mathrm{O}_{3}(8 \mathrm{R})+\mathrm{CO}$ $\rightarrow \mathrm{Ca}_{2} \mathrm{CO}_{4}(8 \mathrm{R})$ Oxidation Reaction, $\Delta E_{\mathrm{CO}}$ Heat of $\mathrm{CO}$ Adsorption, $\Delta U$ Heat of Oxidation Reaction, and $\Delta E_{\mathrm{CO}_{2}}$ Heat of $\mathrm{CO}_{2}$ Adsorption, on Small $\mathrm{Ca}_{2} \mathrm{O}_{3}(8 \mathrm{R})$ Cluster of MOR Calculated at the MP2 and B3LYP Levels Using the 6-31G* Basis Set for All Framework Atoms ${ }^{a}$

\begin{tabular}{lcc}
\hline energy values & B3LYP & MP2 \\
\hline$\Delta E^{\#}$ & 32.4 & \\
$\Delta E_{\mathrm{CO}}$ & 12.4 & 15.1 \\
$\Delta U$ & 72.3 & 68.9 \\
$\Delta E_{\mathrm{CO}_{2}}$ & 20.4 & 25.7 \\
${ }^{a}$ All values are in $\mathrm{kcal} / \mathrm{mol}$. & &
\end{tabular}

superimposed structures (Figure 3c) which were used to construct the extended cluster (Figure 4) allow to evaluate the distortion of the initial ring (Figure $3 b$ ) in course of the optimization (Figure 3a). Computations with the extended models (Figure 4) neither shift effectively the activation barrier, i.e., 33.5 and $22.2 \mathrm{kcal} / \mathrm{mol}$ instead of 35.7 and $23.0 \mathrm{kcal} / \mathrm{mol}$ for $\mathrm{Ca}$ - and $\mathrm{Zn}$-clusters, respectively (Table 5 ), nor change the geometry of the systems. More details on the respective variations between the small and extended models are planned to be presented elsewhere. ${ }^{38}$

Activation barriers were also evaluated using two other density functionals, B3PW91 and B3P86, that led to similar barrier values and TS geometries for $\mathrm{CO} / \mathrm{Zn}_{2} \mathrm{O}_{2}(8 \mathrm{R})$ (Table 5). To determine the reaction coordinate, we applied the QST3 algorithm as supplied with GAUSSIAN03. ${ }^{28}$ Calculated imaginary frequencies along the respective reaction coordinates were $750.3 i, 877.5 i$, and $878.2 i \mathrm{~cm}^{-1}$ for B3LYP, B3PW91, and B3P86, respectively. In all cases, the reaction coordinate corresponded to the vibrations of $\mathrm{CO}$ and one $\mathrm{O}$ atom of the $\mathrm{Me}_{2} \mathrm{O}_{2}$ group. For searching the geometries for the reaction complex, the TS, and the products, we also used the ONIOM approach of B3LYP/6-31G*:HF/3-21G type which converged for the reaction complex only, but not for TS and product complexes. The ONIOM result for the reaction complex nearly coincides with the geometry data obtained at the B3LYP/6-31G* level. The ONIOM models of the B3LYP/6-31G*:AM1 (or PM3 and UFF) type did not converge for the larger clusters.

Finally, geometry optimizations for the reagents and TS were performed at the B3LYP/6-311++G** level starting from the geometries obtained using B3LYP/6-31G*. It resulted in lower activation energy of $21.9 \mathrm{kcal} / \mathrm{mol}$ for the small $\mathrm{CO} / \mathrm{Zn}_{2} \mathrm{O}_{2}(8 \mathrm{R})$ cluster (Table 5). The variations of the heat of $\mathrm{CO}$ oxidation over the $\mathrm{Me}_{2} \mathrm{O}_{2}(8 \mathrm{R})$ cluster do not exceed 5-6\% relative to the value obtained at the B3LYP/6-31G* level, i.e., $110.0 \mathrm{kcal} /$ $\mathrm{mol}$ for $\mathrm{Me}=\mathrm{Zn}$ and $106.9 \mathrm{kcal} / \mathrm{mol}$ for $\mathrm{Me}=\mathrm{Ca}$, when varying either the basis set, or the DFT functional (Table 5).

Tentatively, we also considered variations of the $\mathrm{Al}$ positions in the $8 \mathrm{R}$ ring for $\mathrm{CO} / \mathrm{Ca}_{2} \mathrm{O}_{2}(8 \mathrm{R})$, i.e., $\mathrm{Al}-\mathrm{O}-\mathrm{Si}-\mathrm{O}-\mathrm{Si}-\mathrm{O}-\mathrm{Al}$ and $\mathrm{Al}-\mathrm{O}-\mathrm{Si}-\mathrm{O}-\mathrm{Al}$; it did not result in principle differences (a)

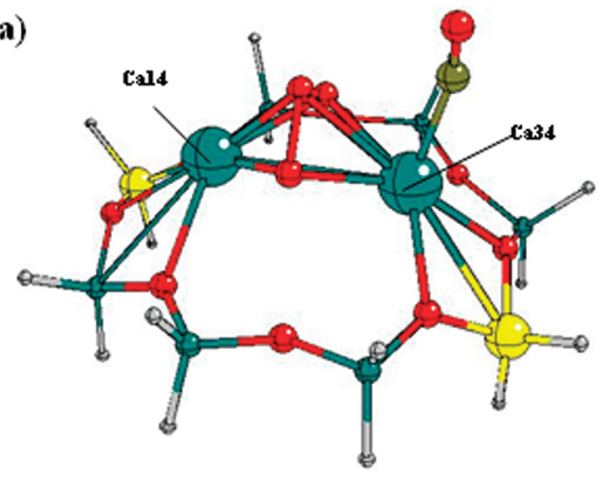

(b)

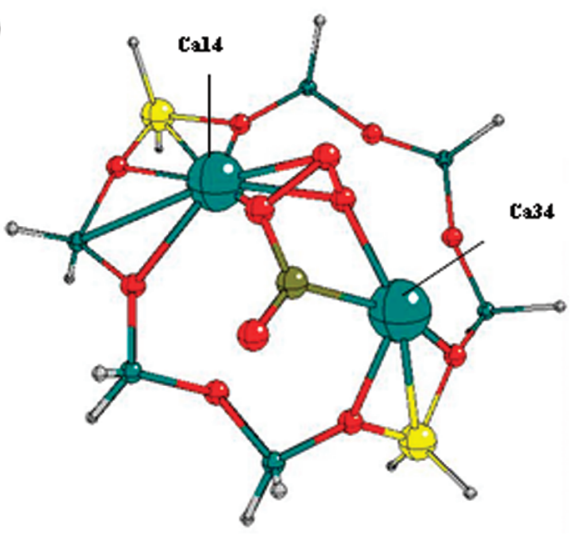

(c)

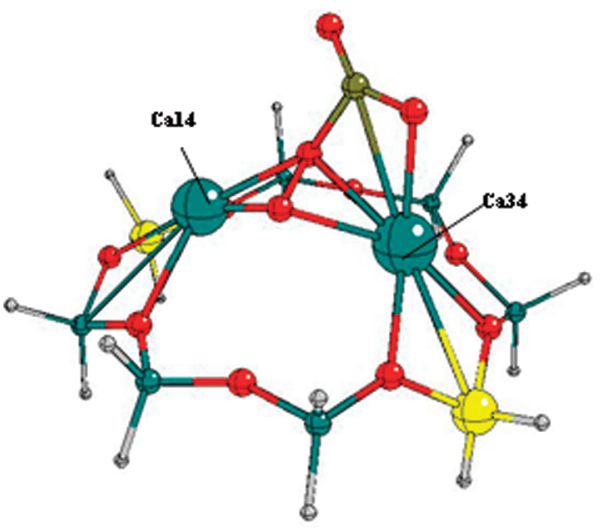

Figure 5. Structures of the reagent (a), transition state (b), and product clusters (c) for $\mathrm{CO}$ oxidation over the small optimized $\mathrm{Ca}_{2} \mathrm{O}_{3}(8 \mathrm{R})$ cluster. The color code corresponds to the one of Figure 2.

regarding the activation energy values (Table 6). The respective reaction complexes are less stable by 15.8 and $26.5 \mathrm{kcal} / \mathrm{mol}$ than the $\mathrm{Al}-\mathrm{O}-\mathrm{Si}-\mathrm{O}-\mathrm{Si}-\mathrm{O}-\mathrm{Si}-\mathrm{O}-\mathrm{Al}$ type complex leading to activation barriers of 37.7 and $35.3 \mathrm{kcal} / \mathrm{mol}$.

CO Oxidation over the $\mathrm{Ca}_{2} \mathrm{O}_{3}(\mathbf{8 R})$ Cluster. We also checked the possibility of the $\mathrm{Ca}_{2} \mathrm{O}_{3}(8 \mathrm{R})$ cluster for $\mathrm{CO}$ oxidation using the same type of process (eq $3 \mathrm{a}$ ). This case turns out to be instructive regarding the evaluation of the reaction parameters at both the MP2 and B3LYP levels using the same 6-31G* basis set (Table 7). As CO is extremely sensitive to electron correlation effects, such a test is strongly required.

If both $\mathrm{O}$ atoms (Figure 2d) are nearly equivalent for $\mathrm{Ca}_{2} \mathrm{O}_{2}(8 \mathrm{R})$, we tried to show which $\mathrm{O}$ atom could react first in the course of $\mathrm{CO}$ oxidation for $\mathrm{Ca}_{2} \mathrm{O}_{3}(8 \mathrm{R})$. We found that any of the two extreme $\mathrm{O}$ atoms of the $\mathrm{O}_{3}$ group can be involved in the $\mathrm{CO}_{2}$ formation at the $\mathrm{Ca}_{2} \mathrm{O}_{3}(8 \mathrm{R})$ cluster. The slightly lower activation energy for $\mathrm{CO}$ oxidation relative to the one is observed over $\mathrm{Ca}_{2} \mathrm{O}_{2}(8 \mathrm{R})$, for example, 32.4 instead of $35.7 \mathrm{kcal} /$ $\mathrm{mol}$ at the B3LYP/6-31G* level. The transition state (TS) 
geometry turns out to be very similar to the case of $\mathrm{CO}$ oxidation over $\mathrm{Ca}_{2} \mathrm{O}_{2}(8 \mathrm{R})$. The search of TS for $\mathrm{CO}$ over $\mathrm{Ca}_{2} \mathrm{O}_{2}(8 \mathrm{R})$ at the MP2/6-31G* level is still in progress. The main differences between $\mathrm{Ca}_{2} \mathrm{O}_{2}(8 \mathrm{R})$ and $\mathrm{Ca}_{2} \mathrm{O}_{3}(8 \mathrm{R})$ in the course of oxidation are related to the heat of reaction which is much larger for $\mathrm{Ca}_{2} \mathrm{O}_{2}(8 \mathrm{R}$ ), i.e., 106.9 (Table 6) versus 72.3 (Table 7) $\mathrm{kcal} / \mathrm{mol}$ at the B3LYP/6-31G* level. We assigned this increase to the strong bidentate $\mathrm{CO}_{2}$ chemisorption over $\mathrm{Ca}_{2} \mathrm{O}(8 \mathrm{R})$ resulting in the $\mathrm{CO}_{3}{ }^{2-}$ anion (Figure $2 \mathrm{f}$ ). The more rigid geometry of the $\mathrm{Ca}_{2} \mathrm{O}_{2}(8 \mathrm{R})$ product does not allow the same symmetric $\mathrm{CO}_{3}{ }^{2-}$ coordination toward $\mathrm{Ca}_{2} \mathrm{O}_{2}$ (Figure 5).

On the basis of the data in Table 7, we conclude that electron correlation effects do not change qualitatively the reaction parameters at different computational levels but should however been checked from a quantitative point of view.

\section{Conclusions}

The oxidation activity of the Ca zeolite forms is well-known from literature. The oxidation mechanism for all cation exchanged zeolites is usually interpreted via "organic molecule $-\mathrm{O}_{2}$ " ion pair over a cation with an essential charge transfer. Nevertheless, it is difficult to apply such idea about ion pair stabilization for example to the $\mathrm{CO}-\mathrm{O}_{2}$ to explain $\mathrm{CO}$ oxidation occurring in $\mathrm{Ca}$ type zeolites. In this paper, another oxidation mechanism is suggested and discussed with respect to $\mathrm{CO}$ oxidation for $\mathrm{Zn}$ - and $\mathrm{Ca}$-cation exchanged zeolites.

Different geometries of $\mathrm{Me}_{2} \mathrm{O}_{2}$ and $\mathrm{Me}_{2} \mathrm{O}_{3}$ oxide moieties in fragments of the $8 \mathrm{R}$ ring of mordenite (MOR) were first modeled for $\mathrm{Me}=\mathrm{Zn}$ and $\mathrm{Ca}$ at the $\mathrm{B} 3 \mathrm{LYP} / 6-31 \mathrm{G}^{*}$ level via the cluster approach. For $\mathrm{Zn}$, the $\mathrm{Zn}_{2} \mathrm{O}_{2}$ and $\mathrm{Zn}_{2} \mathrm{O}_{3}$ moieties are oriented in a plane that is nearly perpendicular to the $8 \mathrm{R}$ ring and passes through both $\mathrm{Zn}$ cations. The $\mathrm{Zn}_{2} \mathrm{O}_{2}$ geometry is very similar to the square type clusters already calculated for $\mathrm{Al}_{2} \mathrm{O}_{2}$ and $\mathrm{Ga}_{2} \mathrm{O}_{2}$, and partly confirmed experimentally for $\mathrm{Ga}_{2} \mathrm{O}_{2}$; however, the $\mathrm{O}-\mathrm{O}$ bond is much shorter in $\mathrm{Zn}_{2} \mathrm{O}_{2}$. The rhomb type $\mathrm{Ca}_{2} \mathrm{O}_{2}$ moiety is parallel to the $8 \mathrm{R}$ ring due to the spatial restrictions for the larger $\mathrm{Ca}$ cation so that both $\mathrm{O}$ atoms are available for adsorbate molecules as compared to the $\mathrm{Zn}_{2} \mathrm{O}_{2}$ one. The $\mathrm{O}_{3}$ type fragment in $\mathrm{Me}_{2} \mathrm{O}_{3}(8 \mathrm{R})$ conserves the common A-letter shape which is oriented notably asymmetrically in the $\mathrm{Zn}_{2} \mathrm{O}_{3}$ cluster and symmetrically in the $\mathrm{Ca}_{2} \mathrm{O}_{3}$ cluster, this last one being elevated over the $8 \mathrm{R}$ ring and cations. The heats of $\mathrm{Ca}_{2} \mathrm{O}_{X}(8 \mathrm{R})$ oxidation by molecular oxygen calculated at the B3LYP/6-31G* level were confirmed at the MP2/6-31G* level for $X=1$ and 2 , both being of the same order of value.

We observed a difference between the possible catalytic cycles based on a series of consequent $\mathrm{Ca}_{2} \mathrm{O}_{X}$ or $\mathrm{Zn}_{2} \mathrm{O}_{X}$ oxides. All of the oxidation steps by molecular oxygen from $\mathrm{Ca}_{2} \mathrm{O}$ to $\mathrm{Ca}_{2} \mathrm{O}_{2}$, from $\mathrm{Ca}_{2} \mathrm{O}$ to $\mathrm{Ca}_{2} \mathrm{O}_{3}$, and from $\mathrm{Ca}_{2} \mathrm{O}_{2}$ to $\mathrm{Ca}_{2} \mathrm{O}_{3}$ are exothermic, whereas for $\mathrm{Me}=\mathrm{Zn}$ only one step from $\mathrm{Zn}_{2} \mathrm{O}$ to $\mathrm{Zn}_{2} \mathrm{O}_{2}$ is exothermic. However, a lower activation barrier for oxidation according to the $\mathrm{Me}_{2} \mathrm{O}_{2}(8 \mathrm{R})+\mathrm{CO} \rightarrow \mathrm{Me}_{2} \mathrm{CO}_{3}(8 \mathrm{R})$ reaction was obtained for $\mathrm{Me}=\mathrm{Zn}$ versus $\mathrm{Me}=\mathrm{Ca}$. A more complete relaxation of the whole moiety including $\mathrm{CO}$ oxidation at $\mathrm{Me}_{2} \mathrm{O}_{2}$ was further considered by adding a layer of 16 oxygen atoms connected to all $\mathrm{Si}$ and $\mathrm{Al}$ atoms. All computations with the extended models or using other DFT correlation functionals, PW91, P86, neither shifted effectively the activation barrier, nor changed the geometry for the $\mathrm{Me}=\mathrm{Zn}$ systems.

Essentially lower heats of $\mathrm{CO}$ oxidation according to the $\mathrm{Ca}_{2} \mathrm{O}_{X}(8 \mathrm{R})+\mathrm{CO} \rightarrow \mathrm{Ca}_{2} \mathrm{CO}_{X+1}(8 \mathrm{R})$ reaction was obtained for $X=3$ versus $X=2$. It was explained due to non complete chemisorption of $\mathrm{CO}_{3}{ }^{2-}$ obtained near the more rigid $\mathrm{Ca}_{2} \mathrm{O}_{2}(8 \mathrm{R})$ fragment. The heat of $\mathrm{CO}$ oxidation over $\mathrm{Ca}_{2} \mathrm{O}_{3}(8 \mathrm{R})$ computed at the B3LYP/6-31G* level was confirmed at the MP2/6-31G* level as well as the heats of $\mathrm{CO}$ and $\mathrm{CO}_{2}$ adsorption. The closeness between the heats of adsorption calculated at the DFT and MP2 levels proves the accuracy of the B3LYP evaluations regarding the thermodynamic parameters for the $\mathrm{CO}$ oxidation processes. Respective activation energies were found to be close for $X=2$ and 3 for the reaction above at the B3LYP/6-31G* level.

Hence, we could suggest the possible realization of closed oxidation catalytic cycle based on the series of the $\mathrm{Ca}_{2} \mathrm{O}_{X}$ and $\mathrm{Zn}_{2} \mathrm{O}_{X}$ oxide clusters at the cationic positions of the zeolites with moderate value of $\mathrm{Si} / \mathrm{Al}$ modulus.

Acknowledgment. The authors thank the FUNDP, the FNRSFRFC, and the Loterie Nationale (Convention 2.4578.02) for the use of the Namur Interuniversity Scientific Computing Facility (iSCF) Centre. The authors also acknowledge the CGRI for financial support in the framework of the Programme de la coopération 2008-2010 entre la Communauté française de Belgique, la Région wallonne et la Fédération de Russie (convention 2008/18342).

\section{References and Notes}

(1) Blatter, F.; Frei, H. J. Am. Chem. Soc. 1993, 115, 7501.

(2) Blatter, F.; Moreau, F.; Frei, H. J. Phys. Chem. 1994, 98, 13403.

(3) Blatter, F.; Frei, H. J. Am. Chem. Soc. 1994, 116, 1812.

(4) Sun, H.; Blatter, F.; Frei, H. J. Am. Chem. Soc. 1994, 116, 7951.

(5) Sun, H.; Blatter, F.; Frei, H. J. Am. Chem. Soc. 1996, 118, 6873.

(6) Panov, A. G.; Larsen, R. G.; Totah, N. I.; Larsen, S. C.; Grassian, V. H. J. Phys. Chem. B 2000, 104, 5706.

(7) Larsen, R. G.; Saladino, A. C.; Hunt, T. A.; Mann, J. E.; Xu, M.; Grassian, V. H.; Larsen, S. C. J. Catal. 2001, 204, 440.

(8) Xu, J.; Mojet, B. L.; van Ommen, J. G.; Lefferts, L. J. Phys. Chem. B 2005, 109, 18361 .

(9) Visser, T.; Nijhuis, T. A.; van der Eerden, A. M. J.; Jenken, K.; Ji, Y. Y.; Bras, W.; Nikitenko, S.; Ikeda, Y.; Lepage, M.; Weckhuysen, B. M. J. Phys. Chem. B 2005, 109, 3822.

(10) Shete, B. S.; Kamble, V. S.; Gupta, N. M.; Kartha, V. B. J. Phys. Chem. B 1998, 102, 5581

(11) Delgass, W. N.; Garten, R. L.; Boudart, M. J. Phys. Chem. 1969, 73, 2970.

(12) Garten, R. L.; Delgass, W. N.; Boudart, M. J. Catal. 1970, 18, 90. (13) Dalla Betta, R. A.; Garten, R. L.; Boudart, M. J. Catal. 1976, 41, 40.

(14) Chen, H.-Y.; El-Malki, El.-M.; Wang, X.; van Santen, R. A.; Sachtler, W. M. H. Catalysis by unique metal ion structures in solid matrices; NATO science series II; Genti, G., Ed.; Kluwer Acad. Publ.: Dordrecht, The Netherlands, 2001; Vol. 13, pp 75-84.

(15) Lei, G. D.; Adelman, B. J.; Sarkany, J.; Sachtler, W. M. H. Appl. Catal., B 1995, 5, 245.

(16) El-Malki, El.-M.; van Santen, R. A.; Sachtler, W. M. H. J. Catal. 2000, 196, 212.

(17) Sayle, D. C.; Catlow, C. R. A.; Gale, J. D.; Perrin, M. A.; Nortier, P. J. Phys. Chem. A 1997, 101, 3331.

(18) Teraishi, K.; Ishida, M.; Irisawa, J.; Kume, M.; Takahashi, Y.; Nakano, T.; Nakamura, H.; Miyamoto, A. J. Phys. Chem. B 1997, 101, 8079.

(19) Catlow, C. R. A.; Bell, R. G.; Gale, J. D.; Lewis, D. W.; Sayle, D. C.; Sinclair, P. E. Catalytic activation and functionalization of light alkanes; Derouane, E. G., Ed.; Kluwer: Dordrecht, The Netherlands, 1998; pp 189-214.

(20) Goodman, B. R.; Schneider, W. F.; Hass, K. C.; Adams, J. B. Catal. Lett. 1998, 56, 183.

(21) Yakovlev, A. L.; Shubin, A. A.; Zhidomirov, G. M.; van Santen, R. A. Cat. Lett. 2000, 70, 175.

(22) Yakovlev, A. L.; Zhidomirov, G. M.; van Santen, R. A. J. Phys. Chem. B 2001, 105, 12297.

(23) Hansen, N.; Heyden, A.; Bell, A. T.; Keil, F. J. J. Phys. Chem. C 2007, 111, 2092.

(24) Gale, J. D. GULP 1.3; Royal Institution/Imperial Colledge: UK, $1992 / 1994$

(25) Schröder, K. P.; Sauer, J.; Leslie, M.; Catlow, C. R. A.; Thomas, J. M. Chem. Phys. Lett. 1992, 188, 320.

(26) Gale, J. D.; Henson, N. J. J. Chem. Soc. Faraday Trans. 1994, 90, 3175 
(27) Yuan, S.; Wang, J.; Li, Y.; Peng, S. J. Mol. Catal. A 2001, 175, 131.

(28) Gaussian 03, Revision C.02; Frisch, M. J., Gaussian, Inc., Wallingford, CT, 2004.

(29) Barbosa, L. A. M. M.; van Santen, R. A. J. Phys. Chem. C 2007, 111,8337

(30) Zhidomirov, G. M.; Larin, A. V.; Trubnikov, D. N.; Vercauteren, D. P. in preparation.

(31) Zhidomirov, G. M.; Shubin, A. A.; Milov, M. A.; Kazansky, V. B.; van Santen, R. A.; Hensen, E. J. M. J. Phys. Chem. C 2008, 112, 3321

(32) Hensen, E. J. M.; Pidko, E. A.; Rane, N.; van Santen, R. A. Angew. Chem., Int. Ed. 2007, 46, 7273.

(33) Shannon, R. D. Acta Cryst. A 1976, 32, 751.
(34) Lacheen, H. S.; Iglesia, E. Chem. Mater. 2007, 19, 1877.

(35) Huber, K. P.; Herzberg, G. Molecular Spectra and Molecular Structure; Constants of Diatomic Molecules; Van Nostrand: New York, 1976; Vol. 4.

(36) Masuda, T.; Tsutsumi, K.; Takahashi, H. J. Colloid Interface Sci. 1980, 77, 238

(37) Savitz, S.; Myers, A. L.; Gorte, R. J. J. Phys. Chem. B 1999, 103, 3687.

(38) Zhidomirov, G. M.; Larin, A. V.; Trubnikov, D. N.; Vercauteren, D. P. J. Mol. Struct. submitted for publication.

JP808449W 